\title{
Effect of Lockdown due to COVID-19 on the Aerosol and Trace Gases Spatial Distribution over India and Adjoining Regions
}

Special Issue:

Special Issue on COVID-19 Aerosol Drivers, Impacts and Mitigation (X)

\section{OPEN ACCESS}

Received: July 13, 2020

Revised: October 20, 2020

Accepted: October 20, 2020

${ }^{*}$ Corresponding Author: vratnam@narl.gov.in

Publisher:

Taiwan Association for Aerosol Research

ISSN: $1680-8584$ print ISSN: 2071-1409 online

(c) Copyright: The Author(s).

This is an open access article distributed under the terms of the Creative Commons Attribution License (CC BY 4.0), which permits unrestricted use, distribution, and reproduction in any medium, provided the original author and source are cited.

\section{Madineni Venkat Ratnam ${ }^{1}$, Perumal Prasad $^{1}$, Sivan Thankamani Akhil Raj ${ }^{1}$, Ibrahim Hoteit ${ }^{2}$}

${ }^{1}$ National Atmospheric Research Laboratory (NARL), Gadanki-517112, India

${ }^{2}$ King Abdullah University of Science and Technology, Thuwal, Saudi Arabia

\section{ABSTRACT}

Significant improvement in the air quality has been reported during the 'Lockdown' being implemented due to the Corona Virus Disease (COVID-19) pandemic in several parts of the globe. Using Ozone Monitoring Instrument (OMI) satellite measurements, we found a $50-60 \%$ reduction in the mean tropospheric columnar Nitrogen dioxide $\left(\mathrm{NO}_{2}\right)$ and planetary boundary layer Sulphur dioxide $\left(\mathrm{SO}_{2}\right.$ ) levels over India and adjoining regions during the lockdown (25 March-7 April 2020) compared to the pre-lockdown periods (8-21 March 2020). Similar decreases in aerosol concentrations over Indo-Gangetic Plain (IGP) and south India during lockdown are noticed in Moderate Resolution Imaging Spectroradiometer (MODIS) measurements, reaching the lowest values in the satellite era. Surprisingly, aerosol concentrations increased significantly (50-70\%) during lockdown over central India when compared to pre-lockdown and climatology (20012019). A Concentration Weighted Trajectory analysis suggests that the air masses traveling from middle-east and Africa are the potential sources for the observed high aerosol concentrations over central India. Changes in the background meteorology (decrease in wind speed and increase in water vapour) during the lockdown made these aerosols stagnant and increased their size over central India, leading to higher AOD. These results suggest that natural sources (long-range transport) dominate anthropogenic pollution sources over India and adjoining regions, at least during the dry season. This finding is important to argue against the common belief that Asian countries are the main sources of pollution when long-range transport, which is a natural source, is the main cause. Lockdown has provided an opportunity to test this through a natural simulation by turning down the anthropogenic activities.

Keywords: Indian continent, COVID-19, Air pollution, Aerosol, Long-range transport, MODIS, OMI

\section{INTRODUCTION}

COVID-19 pandemic became a world threat within a very short time due to its fast rate of spread, leading to thousands of deaths across the world (WHO, 2020). The epicentre of this dangerous flu moved to North America and Europe after a month from its first identified place in Wuhan, China, during December 2019. Within a couple of months, its footprint is being noticed in $200+$ countries, including densely populated countries like India, though its intensity varies from country to country. Social distancing was enforced to combat COVID-19 fast spreading as medicine and vaccination are not yet available.

Like many influenza viruses, COVID-19 was also thought to sustain only in low temperatures and gradually disappears in warm environments. Thus, the background meteorological conditions are expected to affect COVID-19 spread, in particular temperature and humidity. Preliminary results revealed (Gunthe et al., 2020) that COVID-19 spread has a traceable relation with temperature and UV index only and not with the other meteorological parameters (rainfall, humidity, cloud cover etc.,), in line with the results of lanevski et al. (2019) for other types of 
influenza over Europe. A positive (negative) correlation between COVID-19 and temperature (humidity) was also reported over Wuhan, China (Ma et al., 2020). A significant correlation between COVID-19 deaths and temperature over Indonesia was also reported (Tosepu et al., 2020). In contrast, a non-linear relation between temperature and COVID-19 cases was also reported over China. The World Health Organization (WHO, 2020) finally reported that countries with hot weather also have significant numbers of COVID-19 cases. The relation between meteorological conditions and COVID-19 cases is still therefore a point of debate in the scientific community. However, such controversy does not exist when it comes to the improvement in the air quality that has been reported after the implementation of the COVID-19 lockdown in several countries across the globe.

To enforce social distancing, several countries implemented partial to complete 'lockdown' over different periods, spanning days to weeks. Following a sudden reduction in transport, traffic and industry, pollution concentrations started to decrease to minimum levels in several countries including the most populated cities across China and India. The Air Quality Index (AQI) over several parts of the globe improved significantly since enforcing lockdowns. The decline in the levels of pollutants like $\mathrm{PM}_{2.5}, \mathrm{PM}_{10}, \mathrm{SO}_{2}, \mathrm{CO}, \mathrm{NO}_{2}, \mathrm{NO}$, and $\mathrm{CO}$ have been reported in many recent studies including Brazil (Nakada and Urban, 2020), Mainland China (Bauwens et al., 2020; Chen et al., 2020a), Ecuador (Zalakeviciute et al., 2020), South Korea and western Europe (Bauwens et al., 2020), Iran (Broomandi et al., 2020), India (Jain and Sharma 2020; Navinya et al., 2020), Tehran (Faridi et al., 2020), Spain (Tobías et al., 2020), USA (Bauwens et al., 2020; Berman and Ebisu, 2020). Global $\mathrm{CO}_{2}$ also reduced by $17 \%$ when compared to 2019 levels (Le Quéré et al., 2020), though Safarian et al. (2020) reported a $7 \%$ reduction only. At the same time, $\mathrm{O}_{3}$ levels have been reported to increase due to a reduction in $\mathrm{NO}_{x}$ concentrations across several countries (Broomandi et al., 2020; Siciliano et al., 2020).

National Aeronautics and Space Administration (NASA) satellite Images clearly show that during February, the concentrations of Nitrogen dioxide $\left(\mathrm{NO}_{2}\right)$ fell drastically $(30-40 \%)$ over Wuhan (Bauwens et al., 2020). $\mathrm{NO}_{2}$ is mainly produced by vehicles (fuel combustion), industrial sites, bio-mass burning, lightning and thermal power stations. It is a short-lived pollutant, with a life span of about one day in the atmosphere. As a result, this pollutant is mainly found near the emissions sources and can be used as a proxy for the intensity of activity in different sectors (NASA). A similar decrease is also seen in $\mathrm{CO}, \mathrm{CO}_{2}$ and Black Carbon concentrations and air quality is continuing to improve over many countries that remain under lockdown. Using TROPOspheric Monitoring Instrument (TROPOMI) and Ozone Monitoring Instrument (OMI) satellite measurements, a striking reduction in $\mathrm{NO}_{2}$ levels have also been observed over South Korea (24-43\%), Western Europe (Spain and France (30\%), Germany and Belgium (20\%) and U.S.A (20-38\%) (Bauwens et al., 2020). Thus, pollution levels (aerosols and greenhouse gases) decreased in the atmosphere after the COVID-19 outbreak following the implemented lockdown leading to an appreciable improvement in air quality around the globe.

A similar reduction in the pollution level is expected over India, in lines with other countries, in particular, China where pollution concentrations are generally high. In order to investigate the pollution levels over India and adjoining regions, including China, we analysed OMI and Moderate Resolution Imaging Spectroradiometer (MODIS) sensor measurements. Though, improvement in the air quality is observed over India, to our surprise, aerosol concentrations have increased significantly after the lockdown. We have investigated the plausible mechanism for this observed increase in the aerosol concentrations using background meteorology and dynamics including a Concentration Weighted Trajectory (CWT) analysis to identify the sources and present them in this communication.

\section{DATA AND METHODS}

\subsection{MODIS Measurements}

We make use of gridded $\left(1^{\circ} \times 1^{\circ}\right)$ daily mean MODIS observations obtained during 2001-2020 for investigating changes in the Aerosol Optical Depth (AOD) over South East Asia. Aerosol products derived from MODIS have proven to be reliable over oceans, dark and bright land surfaces after recent improvements in the aerosol retrieval algorithms. Over dark surfaces 
(vegetative land and oceans), AOD is retrieved using the Dark-Target (DT) algorithm, and for bright surfaces Deep Blue (DB) algorithms are used (Sayer et al., 2014). Complete details about DT and DB algorithms can be found in Levy et al. (2013). In this study, we used MODIS-Terra merged DT and DB AOD at $550 \mathrm{~nm}$ for the land and ocean (MOD08_D3) C6.1 Level 3 daily AOD. These observations have a spatial resolution of $1^{\circ} \times 1^{\circ}$ with a swath of $2330 \mathrm{~km}$ and 36 spectral bands (Kilpatrick et al., 2015). The dataset is available from https://modis.gsfc.nasa.gov. We also make use of Fire Radiative Power (FRP) obtained from MODIS measurements (https://firms.modap s.eosdis.nasa.gov) to identify the burning activities.

\subsection{OMI Measurements}

In addition to MODIS, AURA Ozone Monitoring Instrument (OMI) daily tropospheric columnar nitrogen dioxide $\left(\mathrm{NO}_{2}\right)$ and planetary boundary layer sulphur dioxide $\left(\mathrm{SO}_{2}\right)$ are analysed. AURA $\mathrm{OMI}$ is a nadir-viewing spectrometer onboard NASA's Aura satellite. The tropospheric columnar $\mathrm{NO}_{2}$ provided by the OMI satellite for all atmospheric conditions where the cloud fraction is less than $30 \%$. OMI NO 2 and $\mathrm{SO}_{2}$ data are available from the NASA Goddard Earth Sciences, Data and Information Services Centre (GES DISC; http://disc.sci.gsfc.nasa.gov).

\subsection{Trace Gas Analyser and Sky-radiometer Observations}

We also make use of ground-based measurements of $\mathrm{NO}_{2}$ and $\mathrm{SO}_{2}$ from HORIBA trace gas analyser located at Gadanki $\left(13.5^{\circ} \mathrm{N}, 79.2^{\circ} \mathrm{E}\right)$ so as to compare the OMI satellite measurements. These analysers have lower detection limits of $0.5 \mathrm{ppb}$ and are well calibrated following the linear calibration method using NIST traceable standards. Further, we make use of AOD measurements from Sky-radiometer (POM-01L, Make: Prede Co. Ltd, Japan) to compare MODIS AOD measurements. This radiometer is an automatic ground-based radiometer that measures the direct solar radiation at the 1-minute interval, and diffuse sky radiance with a $1^{\circ}$ field-of-view with respect to the Sun at 10-minute intervals. Both the direct and diffuse sky radiances are used to retrieve the AOD at 5 wavelengths, viz., 400, 500, 675, 870 and $1020 \mathrm{~nm}$. In the present study, we have used AOD estimated at $550 \mathrm{~nm}$ (re-calculated from known wavelengths by using Angstrom empirical formula) that match with MODIS AOD.

\subsection{NCEP/NCAR and ERA-5 Reanalysis Data}

Daily mean zonal and meridional winds from the National Centers for Environmental Prediction (NCEP)/National Center for Atmospheric Research (NCAR) reanalysis during the lockdown period is used to investigate the role of long-range transport. The details of NCEP/NCAR reanalysis data are given by Kalnay et al. (1996). We also used high resolution ERA-5 reanalysis data (https://cds.climate.copernicus.eu/cdsapp) of relative humidity and winds at 6-hourly intervals to understand their role on the observed enhanced AOD. Note that ERA-5 is the next generation of ERA-Interim with a major improvement in the spatial, temporal and vertical coverage (Hersbach and Dee et al., 2016).

\section{RESULTS AND DISCUSSION}

\subsection{Trace Gases and Aerosol Distribution during Pre- and during Lockdown}

India implemented Bharat Curfew (complete lockdown) on 22 March 2020, followed by a total lockdown from 25 March 2020 to 14 April 2020 (Phase1). A second extension to this lockdown was implemented until 3 May 2020 (Phase 2) with a few exceptions, followed by a third extension until 17 May 2020 (Phase 3) with more exceptions. During the first phase, only essential services were allowed, leading to almost 95\% shut down of the country's activities with travel restrictions and quarantines. As a result, transport, industries, power plants, road dust and construction activity, which are the major sources of air pollution and particulate matter in the atmosphere, reduced drastically.

Aerosols and trace gases levels before and during the lockdown in India and adjoining regions are investigated using satellite measurements. As mentioned earlier, mean tropospheric columnar Nitrogen dioxide $\left(\mathrm{NO}_{2}\right)$ and planetary boundary layer Sulphur dioxide $\left(\mathrm{SO}_{2}\right)$ are obtained from 
OMI and AOD from MODIS satellites. Figs. $1(\mathrm{a})-1$ (c) show the observed spatial distribution of $\mathrm{NO}_{2}$ over India and adjoining regions during pre-lockdown (hereafter referred as PLD) (08-21 March 2020) and during lockdown (hereafter referred as DLD) (25 March-07 April 2020), including the Bharat Curfew day (22 March 2020). In general, higher concentrations over central and northeast India can be noticed during PLD. $\mathrm{NO}_{2}$ levels decreased drastically on the Bharat Curfew day. About $50-60 \%$ decrease in $\mathrm{NO}_{2}$ levels is seen between DLD and PLD periods (Fig. 2(a)). There are some hot spots over north-east India with an increase in $\mathrm{NO}_{2}$ levels particularly over the thermal power plants locations. High concentrations are also seen over head Bay of Bengal (BoB) and north-east China. A similar decrease is also observed in the $\mathrm{SO}_{2}$ measurements shown in Figs. $1(\mathrm{~d})-1(\mathrm{f})$. A decrease of $60 \%$ is observed in planetary boundary layer $\mathrm{SO}_{2}$ levels, particularly in the regions where thermal plants are located (Fig. 2(b)). Similar reductions are also expected in the $\mathrm{CO}, \mathrm{CO}_{2}$ and Black Carbon concentrations (Sharma et al. 2020). However, large concentrations of pollutants over the north-east of China and head BoB are noticeable, irrespective of the India lockdown.

In order to examine the effect of lockdown on aerosols, we analyse AOD, a columnar integrated aerosol concentration in the atmosphere. Figs. $1(\mathrm{~g})-1$ (i) shows the spatial distribution of AOD as observed over India and adjoining regions during PLD and DLD. Large concentrations of aerosol are seen over Indo Gangetic Plain (IGP) covering Punjab, Haryana, Uttar Pradesh, Uttarakhand, Bihar and Central India during PLD. The clean atmosphere persists over north-west and south India. On the curfew day, a clean atmosphere can be noticed except for the IGP and east coastal regions. However, enhancement in the aerosol concentrations is noticeable over south India on

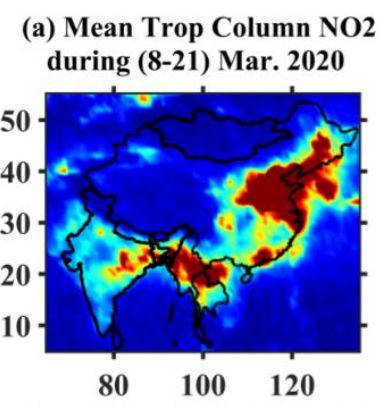

(d) Mean PBL Column SO2

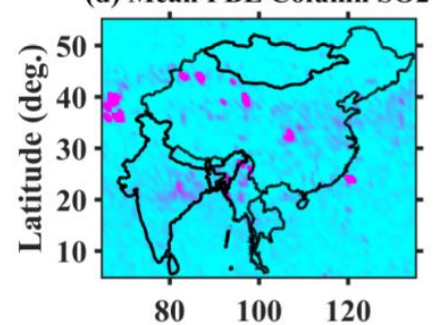

(g) Mean AOD

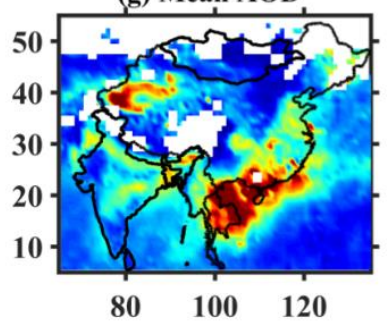

(b) 22-03-2020 (Curfew Day)

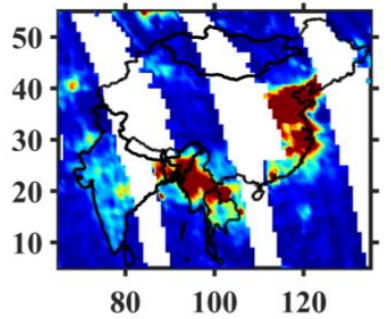

(e) 22-03-2020

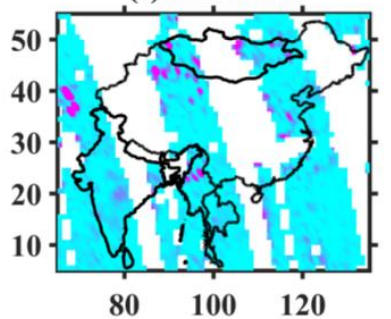

(h) 22-03-2020

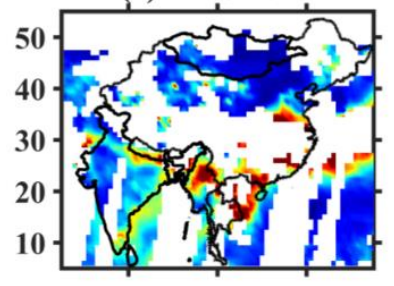

$80 \quad 100 \quad 120$ (c) Mean Trop Column NO2 during (25 Mar. - 07 Apr.) 2020

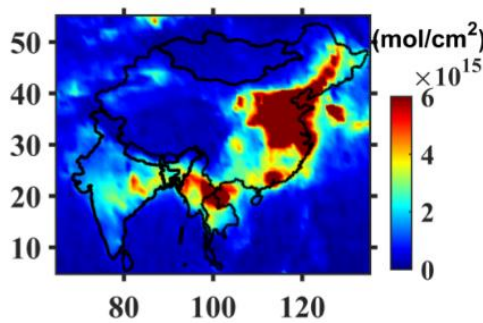

(f) Mean PBL Column SO2

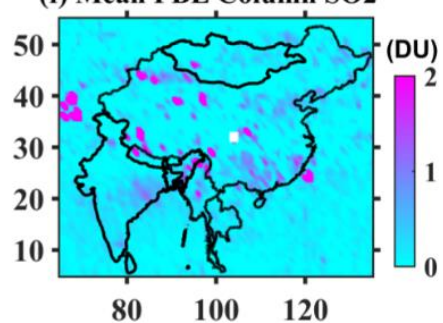

(i) Mean AOD

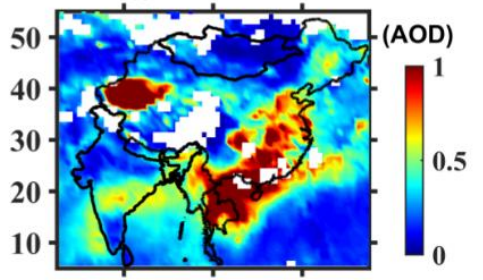

$\begin{array}{lll}80 & 100 & 120\end{array}$

Longitude (deg.)

Fig. 1. (Top Panels) Spatial distribution of $\mathrm{NO}_{2}$ average of 14 days during PLD (08-21 March 2020) and 14 days DLD (25 March-07 April 2020) periods including the Bharat curfew day (22 March 2020) observed by OMI satellite over India and adjoining regions. (Middle Panels) (d) to (f) Same as (a) to (c) but for $\mathrm{SO}_{2}$ distribution. (Bottom Panels) (g) to (i) same as (a) to (c) but for Aerosol Optical Depth from MODIS measurements. 
(a) $\mathrm{NO2}$

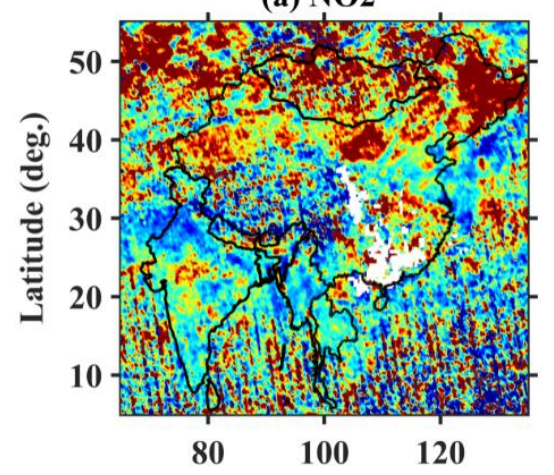

(b) $\mathrm{SO} 2$

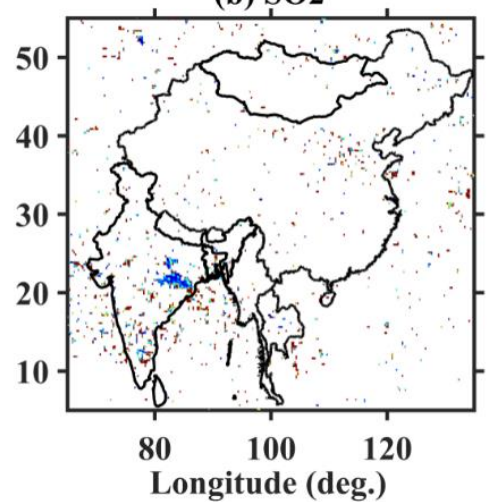

(c) AOD

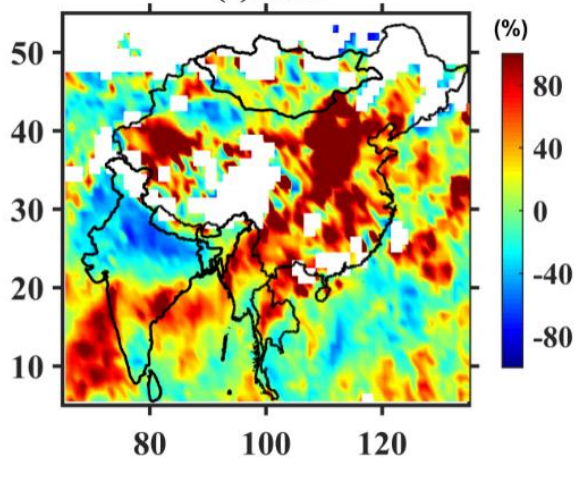

Fig. 2. Percentage difference in (a) mean tropospheric columnar $\mathrm{NO}_{2}$, (b) mean planetary boundary layer columnar $\mathrm{SO}_{2}$ and (c) AOD between DLD (25 March-07 April 2020) and PLD (08-21 March 2020) periods.

the curfew day. About $60-70 \%$ decrease in AOD over the IGP region is noticed. A clean atmosphere persists over north-west and south India. Surprisingly, a similar increase in the magnitude of AOD is seen over Central India and BoB during DLD (Fig. 2(c)). A large increase in AOD is however observed over south east China and Bangladesh including head BoB.

\subsection{Ground Based Observations of Aerosol and Trace Gases during PLD and DLD}

The results of the previous section clearly suggest a 50-60\% decrease in $\mathrm{NO}_{2}$ and a similar decrease in $\mathrm{SO}_{2}$ (only over thermal plant locations) and AOD. However, a similar percentage increase in AOD over central India is also noticed. Before proceeding further, it is essential to discuss their concentrations in relation to the observed values/trends by ground based instruments. As mentioned in section 2, we make use of trace gas analyser measurements of $\mathrm{NO}_{2}$ and $\mathrm{SO}_{2}$ and Sky-radiometer measurements of $\mathrm{AOD}$ obtained from Gadanki $\left(13.5^{\circ} \mathrm{N}, 79.2^{\circ} \mathrm{E}\right)$ to compare the OMI and MODIS satellite measurements, respectively. A comparison between satellite and ground based measurements from 8 March to 7 April 2020 is shown in Fig. 3. The satellite measurements we obtained at the closest grid $\left(78.5^{\circ} \mathrm{E}-80.5^{\circ} \mathrm{E}, 12.5^{\circ} \mathrm{N}-14.5^{\circ} \mathrm{N}\right)$ point to the Gadanki location. Despite a small underestimation in satellite measured AOD when compared to Sky-radiometer observed AOD, their trends match well (Fig. 3(a)). AOD reaches as high as 0.6 during PLD and gradually decreases to a minimum of 0.2 during DLD. However, it is interesting to notice the increase in AOD during the first week of April 2020 in both measurements. In contrast, satellite measurements of $\mathrm{NO}_{2}$ (Fig. 3(b)) and $\mathrm{SO}_{2}$ (Fig. 3(c)) are underestimated and slightly overestimated compared to the ground-based trace gas analyser measurements during PLD and DLD, respectively. A large enhancement in all the concentrations are observed during 13-18 March 2020 in the ground-based instruments due to highly localized event that is not captured in the satellite measurements. The differences between ground based and satellite measurements can be attributed to their sampling size, local emissions etc., Despite some slight shifts in the peaks, their trends match well particularly during the DLD period. A drastic decrease in their concentrations is noticeable reaching values close to their detection limit during the DLD period.

To further assess the quality of the satellite measured concentrations, we also present some of the results at other locations in India using a different network of observations. Sharma et al. (2020) compared the variations in the concentrations over 22 cities of India to those measured during the same period in previous years (2017-2019) and showed overall reductions of 43, 31, 10 and $18 \%$ in $\mathrm{PM}_{2.5}, \mathrm{PM}_{10}, \mathrm{CO}$, and $\mathrm{NO}_{2}$, respectively. They further reported negligible changes in $\mathrm{SO}_{2}$, but $17 \%$ increase in $\mathrm{O}_{3}$ concentrations during the DLD. Jain and Sharma (2020) also carried out a similar analysis over five Indian megacities comparing the concentration changes during March-April 2020 against the March-April 2019 period. Their analysis also showed significant reductions in the $\mathrm{PM}_{2.5}, \mathrm{PM}_{10}, \mathrm{NO}_{2}$ and $\mathrm{CO}$ concentrations over these five cities. There was a reduction of $51 \%$ in $\mathrm{NO}_{2}$. The Air Quality Index (AQI) assessment by Mahato et al. (2020) over New Delhi revealed $50 \%$ reduction in $\mathrm{PM}_{2.5}$ and $\mathrm{PM}_{10}$ concentrations during the DLD when 


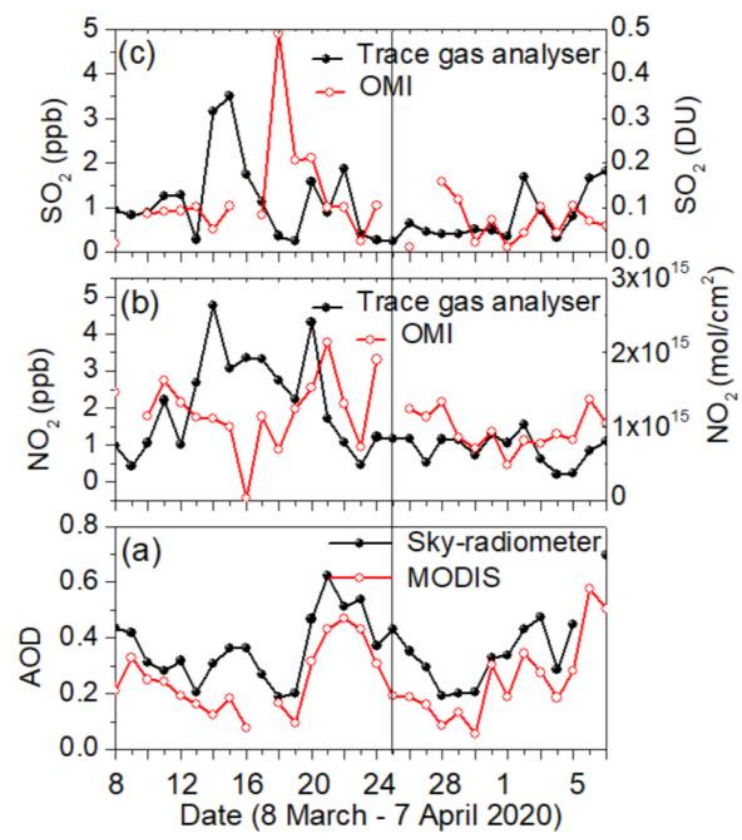

Fig. 3. Comparison between (a) MODIS observed AOD and Sky-radiometer measured AOD, OMI observed (b) $\mathrm{NO}_{2}$ and (c) $\mathrm{SO}_{2}$ and greenhouse gas analyser measured $\mathrm{NO}_{2}$ and $\mathrm{SO}_{2}$ located at Gadanki during PLD and DLD periods. A vertical line is drawn to show the start of lockdown in India.

compared to the PLD. They also reported a reduction in $\mathrm{NO}_{2}$ concentrations by $52 \%$ during DLD. In another study by Navinya et al. (2020) over 17 cities in India, reported a reduction in $\mathrm{NO}_{2}$ varying between 35 and $86 \%$ with a mean reduction of $50 \%$ and a reduction in $\mathrm{SO}_{2}$ is highly random. Note that these are point measurements and to the best of our knowledge none of the studies has investigated over India to analyse the variation in these trace gases and aerosol concentrations using satellite measurements. It is clear that except for a change of magnitude, these satellite measurements capture the gross features that prevailed during PLD and DLD periods. It is thus safe to consider the satellite measurements to study the variability during PLD and DLD, at least qualitatively.

\subsection{Plausible Explanation for the Observed Increase in the Aerosol \\ Concentration during DLD over Central India}

In this subsection, we have discussed the plausible explanation for the observed increase in the aerosol concentration during DLD over central India. In general, aerosols are mainly produced by natural and anthropogenic activities in the atmosphere. The lockdown resulted in a considerable reduction in the anthropogenic aerosols, particularly those produced by transport and industrial activities. Though pollution due to vehicular transport decreased significantly, household usage (wood burning) is expected to remain at a similar level, or might have even slightly increased, as people are locked in their homes. Pollution from industries and thermal power plants also has come down due to the forcible shut down and lesser power demand (as several industries are either not working or working at a reduced level). However, the natural productions of aerosols are still continued. There are no potential emissions due to the lockdown except for bio-mass burning of crop waste which continued and this will remain as background. Fire Radiative Power (FRP) obtained from MODIS measurements can be used as a proxy for the bio-mass burning and is shown in Fig. 4. During PLD (Fig. 4(a)), FRP of 5-10 MW is noticed mainly over south India and IGP regions. Higher power is noticed with few red spots over north east India, Bangladesh and head BoB including east China. Relatively less FRP is noticed over central India. During PLD (Fig. 4(b)), similar FRP is noticed over the regions mentioned above with more spots over central India and IGP regions and fewer spots over south east China. During 8-20 April 2020, relatively higher FRP is observed compared to the period 25 March to 7 April 2020, but the 
(a) FRP during (8-21) Mar. 2020

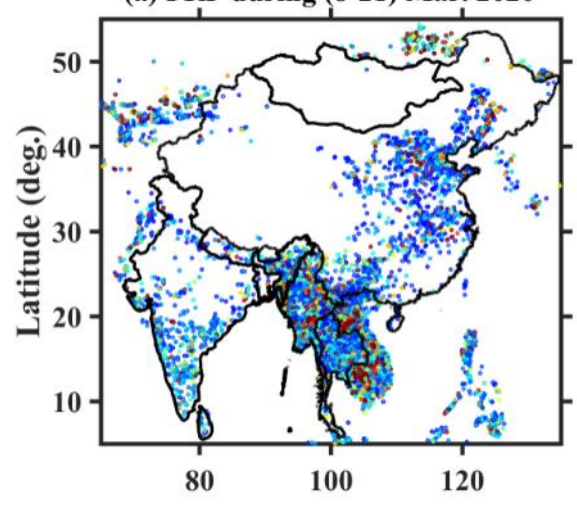

(b) FRP during (25 Mar. - 07 Apr.) 2020

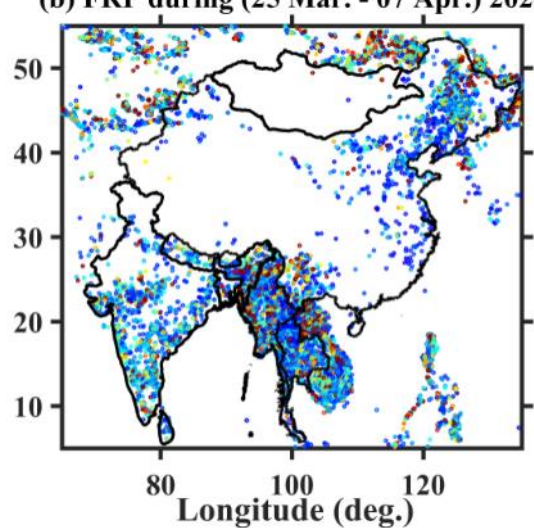

(c) FRP during (08-20) Apr. 2020

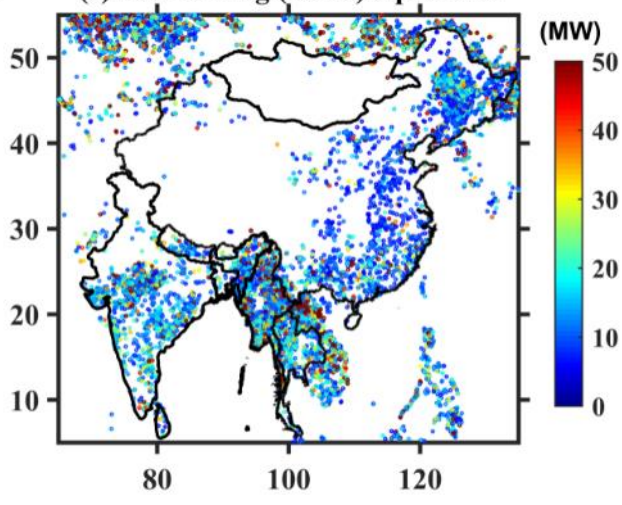

Fig. 4. Fire radiative power observed over south east Asia during (a) 8-21 March 2020 (PLD), (b) 25 March to 07 April 2020 and (c) 8-20 April 2020 (DLD Phase1) obtained from MODIS measurements.

IGP region remains clean. However, hot spots of FRP observed over north BoB, including Bangladesh and east of China, may contribute to some extent to the enhanced $\mathrm{NO}_{2}$ levels and $A O D$ as shown in Fig. 1. In general, one can conclude that there is no significant change in FRP between PLD and DLD thus, observed burning activity will remain as background.

The current dry season with high winds is mainly responsible for the production and transport of dust, significantly contributing to AOD especially over central India. Fig. 5 shows the mean wind vectors obtained from NCEP reanalysis averaged over the DLD period at $850 \mathrm{hPa}, 700 \mathrm{hPa}$, $500 \mathrm{hPa}$ and $300 \mathrm{hPa}$. The reversal in winds starts over the middle-east and Africa where the largest source of desert dust is located. Dust transported from these regions is pooled into an anti-cyclonic structure seen in the wind vectors from $500 \mathrm{hPa}$ to $300 \mathrm{hPa}$ over central India, including head BoB and south-east China.

In order to further investigate the potential transport of aerosols over large geographical scales, Concentration Weighted Trajectory (CWT) maps of AOD for Central India are used. CWT includes atmospheric concentrations combined with back-trajectories and residence time information to identify air parcels that may be responsible for high concentration observed at a given region (Fleming et al., 2012; Wang et al., 2017). Very recently, Chen et al. (2020b) used CWT to identify the potential sources for haze formation over a few cities in Chinese. In the present study, to identify the transport pathways of aerosols, 72-h back trajectories were calculated at $1.5 \mathrm{~km}(850 \mathrm{hPa}), 2.5 \mathrm{~km}(700 \mathrm{hPa})$ and $5.5 \mathrm{~km}(500 \mathrm{hPa})$ height above the ground level. The calculations were carried out at $3 \mathrm{~h}$ (UTC) during the DLD period (25 March-7 April 2020) with $0.25^{\circ} \times 0.25^{\circ}$ grid cells. CWT analysis of AOD at $1.5 \mathrm{~km}, 2.5 \mathrm{~km}$ and $5.5 \mathrm{~km}$ shown in Fig. 6 suggest that the sources of the observed aerosol levels are located in Africa. Except for the lowest altitude $(1.5 \mathrm{~km})$, all the trajectories start from long-range. At $1.5 \mathrm{~km}$ altitude, air pathways from the south-east also contribute to the observed AOD. Thus, elevated aerosol layers through long-range transport contribute significantly to the total AOD observed over central India, though particulate matter decreases near the surface during the lockdown.

To assess the role of meteorology and dynamics on the observed increase in AOD over central India and China, zonal winds observed at $850 \mathrm{hPa}, 700 \mathrm{hPa}$ and $500 \mathrm{hPa}$ averaged during PLD and DLD periods are shown in Fig. S1. In general, zonal winds are very weak at $850 \mathrm{hPa}$ and blow westward and eastward in south India and north India, respectively, with increasing intensity at higher levels. Westward (eastward) winds become weaker (stronger) at $500 \mathrm{hPa}$ with a magnitude exceeding $15 \mathrm{~m} \mathrm{~s}^{-1}$. The difference in the zonal wind between PLD and DLD periods shown in Figs. $7(\mathrm{a})-7$ (c) reveals a decrease in the zonal wind over central India. Note that reduction in wind speed is less at $850 \mathrm{hPa}\left(2-4 \mathrm{~m} \mathrm{~s}^{-1}\right)$ when compared to $700 \mathrm{hPa}\left(4-6 \mathrm{~m} \mathrm{~s}^{-1}\right)$ and $500 \mathrm{hPa}(6-$ $\left.10 \mathrm{~m} \mathrm{~s}^{-1}\right)$. In general, there is a decrease in wind speed by $50 \%$. A similar decrease in the zonal wind is also seen over China but at all pressure levels. These reduced wind speeds confine pollutants for a longer time. Further, the relative humidity observed at $850 \mathrm{hPa}, 700 \mathrm{hPa}$ and $500 \mathrm{hPa}$ averaged during PLD and DLD periods are shown in Fig. S2. In general, higher relative humidity is observed over central India and China during both the periods. The difference in 
(a) Mean Wind vector at $300 \mathrm{hPa}$

during (25 Mar. - 7 Apr.) 2020

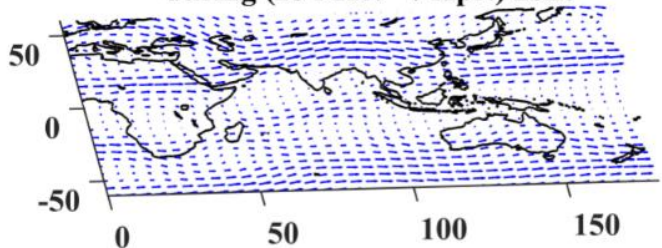

(b) $500 \mathrm{hPa}$

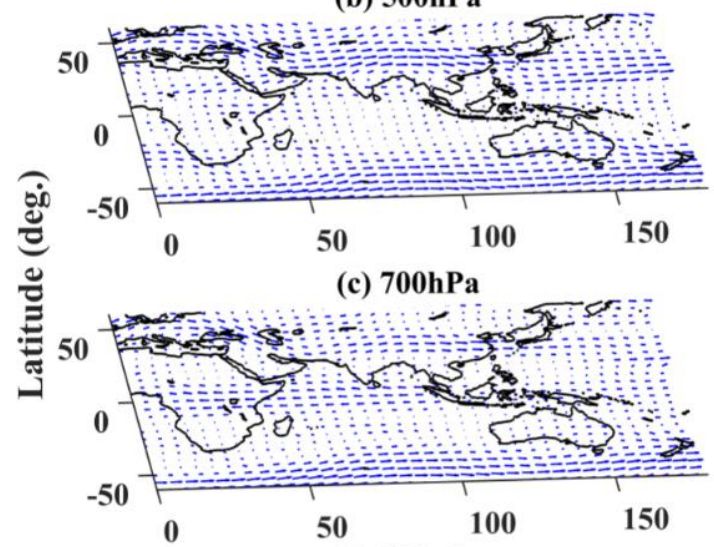

(d) $850 \mathrm{hPa}$

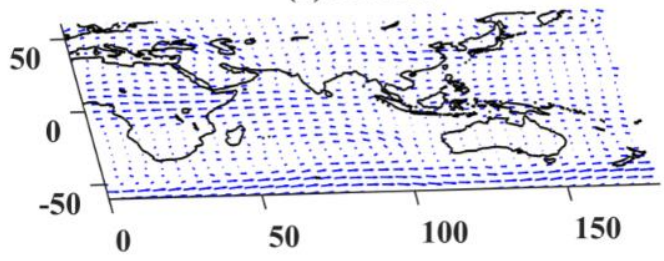

Longitude (deg.)

Fig. 5. Mean wind vectors obtained from NCEP reanalysis products during the DLD period (25 March-7 April 2020) at different pressure levels.

relative humidity between the PLD and DLD periods shown in Figs. $7(d)-7(f)$ reveals a $20 \%$ increase during lockdown over India, particularly at $500 \mathrm{hPa}$. A similar increase in relative humidity is also seen over China but at all pressure levels. This increase in relative humidity will act to increase the aerosol size leading to higher AOD. Thus, meteorology and dynamics play an important role in the observed increase in AOD over central India and China during the lockdown. The effect of reduced wind speeds and an increase in relative humidity on the observed enhanced pollution within China was already reported by Le et al. (2020). However, here we show that an elevated aerosol layer (above $500 \mathrm{hPa}$ ), through long-range transport and background meteorology and dynamics, is the main reason for the observed increase in AOD during DLD over central India.

\subsection{Percentage Contribution of Natural and Anthropogenic Sources to the Observed AOD}

One important aspect that needs to be considered while dealing with PLD and DLD periods is vertical mixing. In general, pollution levels decrease at the surface from winter to summer because of enhanced vertical mixing due to an increase in the boundary layer (Venkat Ratnam et al., 2018). The changes observed here include both the natural changes as well as the changes in aerosol emissions during the lockdown. Comparing the present AOD data with the previous year's averaged over the lockdown period will help to delineate the natural vs. anthropogenic production over India. Fig. 8 shows the percentage difference in AOD between the DLD period and the climatology over the same period from MODIS measurements averaged over 2001-2019. More than $50 \%$ of the observed increase in AOD over central India, head BoB and south east China is associated with natural sources i.e., through long-range transport. 
(a) $5500 \mathrm{~m}$

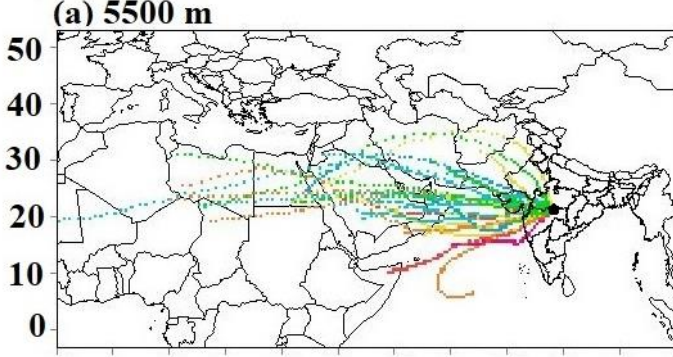

(b) $2500 \mathrm{~m}$

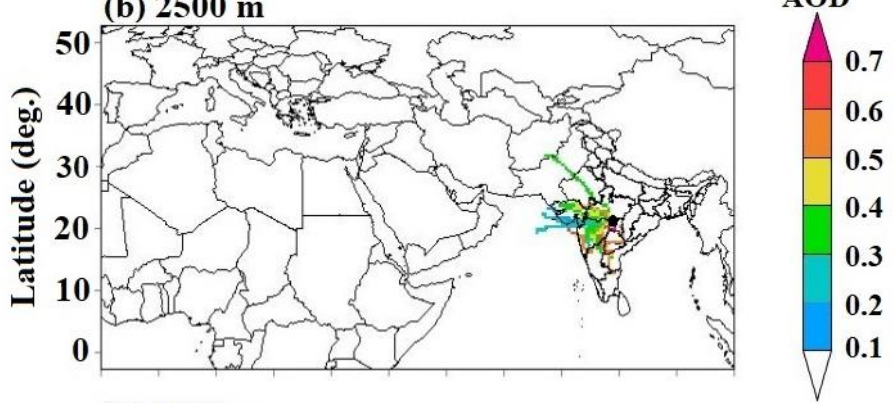

(c) $1500 \mathrm{~m}$

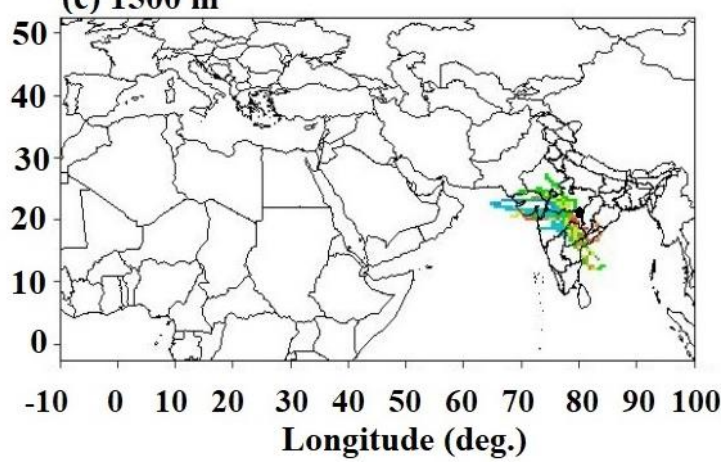

Fig. 6. Concentration weighted trajectory (CWT) maps of AOD for Central India during the DLD period (25 March-7 April 2020). Star denotes centre of central India.

Thus, it is clear that though the air quality has improved following the drastic decrease in gaseous pollutants, and to some extent particulate matter at the surface due to vehicular transport, but total aerosol loading (AOD) in the atmosphere increased drastically over central India. Since there was no significant change in the local emissions due to biomass burning this year compared to previous years, its contribution remains more or less the same. This observation suggests that the large-scale long-range transport plays an important role in the total aerosol loading over central India. 'Lockdown' allowed us to test this hypothesis as a natural laboratory. It also suggests that the gas-to-particle conversion is not very significant as AOD has increased though gaseous pollutants drastically decreased. This point needs more careful analysis in the future. Such quantification is necessary to combat the wide-spread belief that Asian countries are to blame for the generally observed high pollution levels when long-range transport, which is a natural source, is the main cause.

\section{SUMMARY AND CONCLUSIONS}

In this study, we have investigated the effect of the lockdown due to COVID-19 on the air pollution levels over India and adjoining regions using (OMI and MODIS) satellite measurements. The measurements are separated by averaging 14 days during PLD (pre-Lockdown) and DLD (during lockdown) periods. Highlights in the observed results are summarized below:

1. $50-60 \%$ reduction in the mean tropospheric columnar Nitrogen dioxide $\left(\mathrm{NO}_{2}\right)$ and planetary boundary layer Sulphur dioxide $\left(\mathrm{SO}_{2}\right)$ levels (only over thermal plants locations) is observed 
(c) Difference in Wind at $500 \mathrm{hPa}$

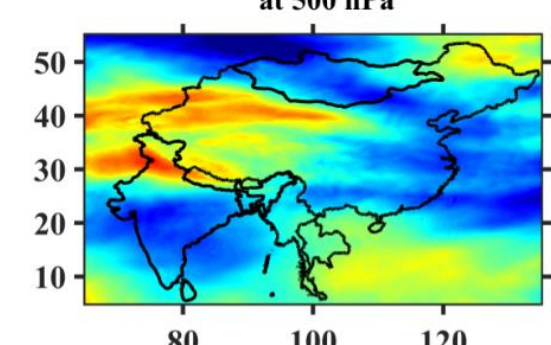

(b) $700 \mathrm{hPa}$

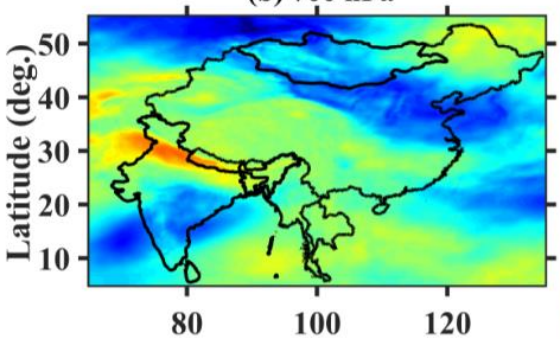

(a) $850 \mathrm{hPa}$

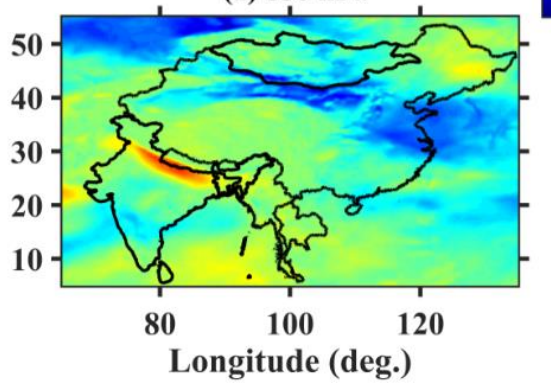

(f) Difference in Relative Humidity at $500 \mathrm{hPa}$

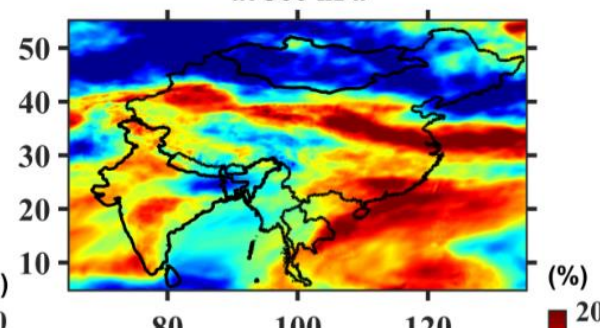

(e) $700 \mathrm{hPa}$

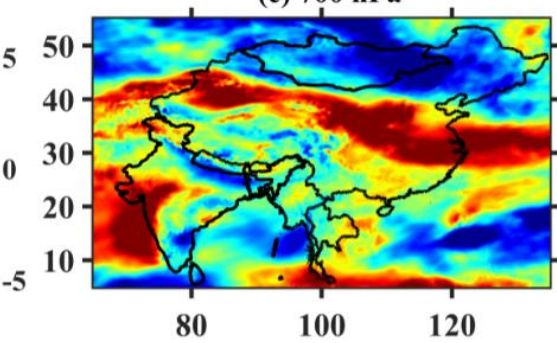

(d) $850 \mathrm{hPa}$

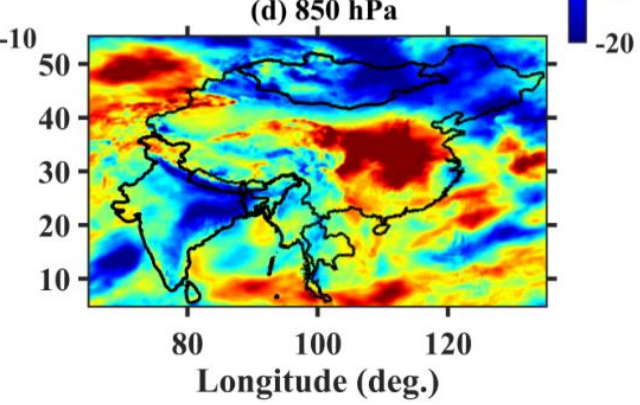

Fig. 7. Difference in zonal wind observed at (a) $850 \mathrm{hPa}$, (b) $700 \mathrm{hPa}$ and (c) $500 \mathrm{hPa}$ between PLD and DLD by ERA- 5 reanalysis. (d)-(f) same as (a)-(c) but for relative humidity.

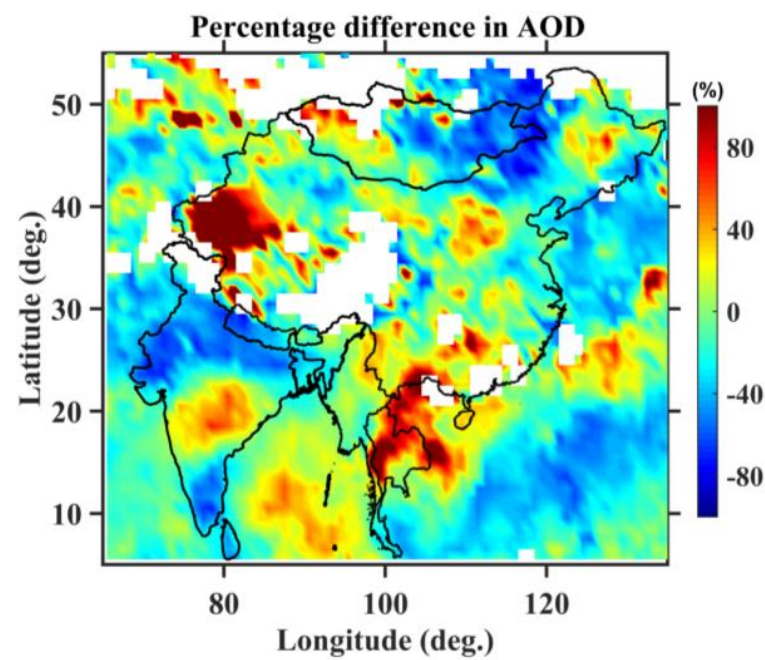

Fig. 8. Percentage difference in AOD between the DLD period (25 March to 07 April 2020) and climatology obtained during the same days averaged during 2001-2019 from MODIS measurements.

during the COVID-19 lockdown over India. When compared to China, Western Europe and South Korea, reduction in $\mathrm{NO}_{2}$ during DLD are higher over India and adjoining regions.

2. Similar magnitude reduction is also observed in Aerosol Optical Depth (AOD) over IGP and south India during DLD, reaching the lowest levels in the satellite era. 
3. However, more than $50 \%$ increase in AOD levels is observed over central India DLD. A Concentrated Weighted Trajectory (CWT) analysis suggests that the potential sources lie in Africa and reach central India through long-range transport.

4. Fire Radiative Power (FRP) obtained from MODIS showed no significant change during PLD and DLD. Thus, anthropogenic activities remain more or less the same during these periods.

5. Long-range transport is contributing more than $50 \%$ to the total aerosol loading over India and adjoining regions (Year 2020 vs. Years 2001-2019), suggesting that natural sources dominate anthropogenic emissions at least during the dry season.

6. A reduction in zonal wind and an increase in relative humidity particularly above $500 \mathrm{hPa}$ led to stagnant aerosol concentrations and an increase in the aerosol size leading to higher AOD over central India.

Thus, it is prudent to conclude that large scale meteorology and dynamics plays an important role in the total aerosol loading over India and adjoining regions.

\section{ADDITIONAL INFORMATION}

\section{DATA AVAILABILITY}

Satellite (OMI and MODIS), and model reanalysis (ERA-5 and NCEP/NCAR) datasets are freely accessible to the public from their respective websites (https://modis.gsfc.nasa.gov \& http://disc.sci.gsfc.nasa.gov).

\section{AUTHOR CONTRIBUTION}

MVR conceived the idea and written the initial manuscript and PP and STA did the data analysis. IH helped in the discussion. All the authors edited the manuscript.

\section{COMPETING INTEREST}

The authors declare no competing interests.

\section{ACKNOWLEDGEMENTS}

We thank OMI, MODIS, HYSPLIT, ERA-5 and NCEP/NCAR teams for making observations freely available through their respective sites. We thank Sai Krishanaveni and Chaithanya D Jain for providing $\mathrm{AOD}$ data and $\mathrm{NO}_{2}$ and $\mathrm{SO}_{2}$ data, respectively, used in the present study. We would like to thank B.V. Krishna Murthy and A. Jayaraman for fruitful discussions.

\section{SUPPLEMENTARY MATERIAL}

Supplementary data associated with this article can be found in the online version at https://doi.org/10.4209/aaqr.2020.07.0397

\section{REFERENCES}

Bauwens, M., Compernolle, S., Stavrakou, T., Müller, J.F., Gent, J. van, Eskes, H., Levelt, P.F., van $\operatorname{der}$ A, R., Veefkind, J.P., Vlietinck, J., Yu, H., Zehner, C. (2020). Impact of coronavirus outbreak on $\mathrm{NO}_{2}$ pollution assessed using TROPOMI and OMI observations. Geophys. Res. Lett. 47, e2020GL087978. https://doi.org/10.1029/2020GL087978

Berman, J.D., Ebisu, K. (2020). Changes in U.S. air pollution during the COVID-19 pandemic. Sci. Total Environ. 739, 139864. https://doi.org/10.1016/j.scitotenv.2020.139864

Broomandi, P., Karaca, F., Nikfal, A., Jahanbakhshi, A., Tamjidi, M., Kim, J.R. (2020). Impact of COVID-19 event on the air quality in Iran. Aerosol Air Qual. Res. 20, 1793-1804. https://doi.org/10.4209/aaqr.2020.05.0205

Chen, Q.X., Huang, C.L., Yuan, Y., Tan, H.P. (2020a). Influence of COVID-19 event on air quality 
and their association in Mainland China. Aerosol Air Qual. Res. 20, 1541-1551. https://doi.org/10.4209/aaqr.2020.05.0224

Chen, X., Yu, S., Wang, L., Li, Z., Zhang, Y., Li, M., Mehmood, K., Liu, W., Li, P., Lichtfouse, E., Rosenfeld, D., Seinfeld, J.H. (2020b). Common source areas of air pollution vary with haze intensity in the Yangtze River Delta, China. Environ. Chem. Lett. 18, 957-965. https://doi.org/10.1007/s10311-020-00976-0

Faridi, S., Yousefian, F., Niazi, S., Ghalhari, M.R., Hassanvand, M.S., Naddafi, K. (2020). Impact of SARS-CoV-2 on ambient air particulate matter in Tehran. Aerosol Air Qual. Res. 20, 1805-1811. https://doi.org/10.4209/aaqr.2020.05.0225

Fleming, Z.L., Monks, P.S., Manning, A.J. (2012). Review: Untangling the influence of air-mass history in interpreting observed atmospheric composition. Atmos. Res. 104-105, 1-39. https://doi.org/10.1016/j.atmosres.2011.09.009

Gunthe, S.S., Swain, B., Patra, S.S., Amte, A. (2020). On the global trends and spread of the COVID19 outbreak: preliminary assessment of the potential relation between location-specific temperature and UV index. J. Public Health https://doi.org/10.1007/s10389-020-01279-y

Hersbach, H., Dee, D. (2016). ERA5 reanalysis is in production, ECMWF Newsletter, Vol. 147, p. 7, https://www.ecmwf.int/en/newsletter/147/news/era5-reanalysis-production (accessed 14 November 2018).

lanevski, A., Zusinaite, E., Shtaida, N., Kallio-Kokko, H., Valkonen, M., Kantele, A., Telling, K., Lutsar, I., Letjuka, P., Metelitsa, N., Oksenych, V., Dumpis, U., Vitkauskiene, A., Stašaitis, K., Öhrmalm, C., Bondeson, K., Bergqvist, A., Cox, R.J., Tenson, T., Merits, A., Kainov, D.E. (2019). Low temperature and low UV indexes correlated with peaks of influenza virus activity in northern Europe during 2010-2018. Viruses 11, 207. https://doi.org/10.3390/v11030207

Jain, S., Sharma, T. (2020). Social and travel lockdown impact considering coronavirus disease (COVID-19) on air quality in megacities of India: Present benefits, future challenges and way forward. Aerosol Air Qual. Res. 20, 1222-1236. https://doi.org/10.4209/aaqr.2020.04.0171

Kalnay, E., Kanamitsu, M., Kistler, R., Collins, W., Deaven, D., Gandin, L., Iredell, M., Saha, S., White, G., Woollen, J., Zhu, Y., Chelliah, M., Ebisuzaki, W., Higgins, W., Janowiak, J., Mo, K.C., Ropelewski, C., Wang, J., Leetmaa, A., Reynolds, R., Jenne, R., oseph, D. (1996). The NCEP/NCAR 40-year reanalysis project. Bull. Am. Meteorol. Soc. 77, 437-472. https://doi.org/10.1175/152 0-0477(1996)077<0437:TNYRP>2.0.CO;2

Kilpatrick, K.A., Podestá, G., Walsh, S., Williams, E., Halliwell, V., Szczodrak, M., Brown, O.B., Minnett, P.J., Evans, R. (2015). A decade of sea surface temperature from MODIS. Remote Sens. Environ. 165, 27-41. https://doi.org/10.1016/j.rse.2015.04.023

Le Quéré, C., Jackson, R.B., Jones, M.W., Smith, A.J.P., Abernethy, S., Andrew, R.M., De-Gol, A.J., Willis, D.R., Shan, Y., Canadell, J.G., Friedlingstein, P., Creutzig, F., Peters, G.P. (2020). Temporary reduction in daily global $\mathrm{CO}_{2}$ emissions during the COVID-19 forced confinement. Nat. Clim. Change 10, 647-653. https://doi.org/10.1038/s41558-020-0797-x

Le, T., Wang, Y., Liu, L., Yang, J., Yung, Y.L., Li, G., Seinfeld, J.H. (2020). Unexpected air pollution with marked emission reductions during the COVID-19 outbreak in China. Science 369, 702706. https://doi.org/10.1126/science.abb7

Levy, R.C., Mattoo, S., Munchak, L.A., Remer, L.A., Sayer, A.M., Patadia, F., Hsu, N.C. (2013). The collection 6 MODIS aerosol products over land and ocean. Atmos. Meas. Tech. 6, 2989-3034. https://doi.org/10.5194/amt-6-2989-2013

Ma, Y., Zhao, Y., Liu, J., He, X., Wang, B., Fu, S., Yan, J., Niu, J., Zhou, J., Luo, B. (2020). Effects of temperature variation and humidity on the death of COVID-19 in Wuhan, China. Sci. Total Environ. 724, 138226. https://doi.org/10.1016/j.scitotenv.2020.138226

Mahato, S., Pal, S., Ghosh, K.G. (2020). Effect of lockdown amid COVID-19 pandemic on air quality of the megacity Delhi, India. Sci. Total Environ. 730, 139086. https://doi.org/10.1016/j.scitoten v.2020.139086

Nakada, L.Y.K., Urban, R.C. (2020). COVID-19 pandemic: Impacts on the air quality during the partial lockdown in São Paulo state, Brazil. Sci. Total Environ. 730, 139087. https://doi.org/10.1 016/j.scitotenv.2020.139087

Navinya, C., Patidar, G., Phuleria, H.C. (2020). Examining effects of the COVID-19 national lockdown on ambient air quality across urban India. Aerosol Air Qual. Res. 20, 1759-1771. https://doi.org/10.4209/aaqr.2020.05.0256 
Safarian, S., Unnthorsson, R., Richter, C. (2020). Effect of coronavirus disease 2019 on $\mathrm{CO}_{2}$ emission in the world. Aerosol Air Qual. Res. 20, 1197-1203. https://doi.org/10.4209/aaqr.20 20.0.0151

Sayer, A.M., Munchak, L.A., Hsu, N.C., Levy, R.C., Betten-hausen, C., Jeong, M.J. (2014). MODIS collection 6 aerosol products: Comparison between Aqua's e-Deep Blue, Dark Target, and "merged" datasets, and usage recommendations. J. Geophys. Res. 119, 13965-13989. https://doi.org/10.1002/2014JD022453

Sharma, S., Zhang, M., Anshika, Gao, J., Zhang, H., Kota, S.H. (2020). Effect of restricted emissions during COVID-19 on air quality in India. Sci. Total Environ. 728, 138878. https://doi.org/10.10 16/j.scitotenv.2020.138878

Siciliano, B., Dantas, G., da Silva, C.M., Arbilla, G. (2020). Increased ozone levels during the COVID19 lockdown: Analysis for the city of Rio de Janeiro, Brazil. Sci. Total Environ. 737, 139765. https://doi.org/10.1016/j.scitotenv.2020.139765

Tobías, A., Carnerero, C., Reche, C., Massagué, J., Via, M., Minguillón, M.C., Alastuey, A., Querol, $X$. (2020). Changes in air quality during the lockdown in Barcelona (Spain) one month into the SARS-CoV-2 epidemic. Sci. Total Environ. 726, 138540. https://doi.org/10.1016/j.scitotenv.202 0.138540

Tosepu, R., Gunawan, J., Effendy, D.S., Ahmad, L.O.A.I., Lestari, H., Bahar, H., Asfian, P. (2020). Correlation between weather and Covid-19 pandemic in Jakarta, Indonesia. Sci. Total Environ. 725, 138436. https://doi.org/10.1016/j.scitotenv.2020.138436

Venkat Ratnam, M., Prasad, P., Roja Raman, M., Ravikiran, V., Vijaya Bhaskara Rao, S., Krishna Murthy, B.V., Jayaraman, A. (2018). Role of dynamics on the formation and maintenance of the elevated aerosol layer during monsoon season over south-east peninsular India. Atmos. Environ. 188, 43-49. https://doi.org/10.1016/j.atmosenv.2018.06.023

Wang, S., Yu, S., Li, P., Wang, L., Mehmood, K., Liu, W., Yan, R. and Zheng, X. (2017). A study of characteristics and origins of haze pollution in Zhengzhou, China, based on observations and hybrid receptor models. Aerosol Air Qual. Res. 17, 513-528. https://doi.org/10.4209/aaqr.201 6.06 .0238

World Health Organization (WHO) (2020). Coronavirus disease (COVID-19) outbreak https://www.who.int/emergencies/diseases/novel-coronavirus-2019

Zalakeviciute, R., Vasquez, R., Bayas, D., Buenano, A., Mejia, D., Zegarra, R., Diaz, A., Lamb, B. (2020). Drastic improvements in air quality in ecuador during the COVID-19 outbreak. Aerosol Air Qual. Res. 20, 1783-1792. https://doi.org/10.4209/aaqr.2020.05.0254 